\title{
Representações Sociais do uso popular de plantas medicinais: experiência em uma comunidade rural
}

\section{Social Representation of the popular use of medicinal plants: experience in a rural community}

Nelma BALDIN ${ }^{1}$

Patricia Mary Real ACOSTA²

Resumo

Abstract

O artigo é um recorte da pesquisa realizada com crianças do $5^{\circ}$ ano do ensino fundamental de uma escola municipal e suas respectivas mães e avós, em uma comunidade rural localizada em Joinville-SC. O objetivo centrou-se na busca das representaçóes sociais, culturais e econômicas do uso popular de plantas medicinais pela comunidade. Utilizou-se da metodologia qualitativa fundamentada na teoria das representaçóes sociais e no método fenomenológico. Observou-se que a maioria da população estudada tem alguma espécie de planta medicinal cultivada nas hortas caseiras. $\mathrm{E}$ a forma mais comum do uso dessas plantas é o chá, ou infusão, e emplastro.

Palavras-chave: Representaçóes Sociais. Plantas Medicinais. Educação Ambiental.

The article is part of a research carried with children in the 5 th grade of elementary school of the Municipal School and their mothers and grandmothers, of a rural community located in Joinville (SC). The objective focused to seek the social, cultural and economic representations of the popular use of medicinal plants by the community. We used the qualitative methodologie based on the theory of social representations and phenomenological method. It was observed that the majority of the study population, have some kind of medicinal plant cultivated in their home gardens. The most common form of the use of these plants as tea, or infusion, and plaster.

Keywords: Social Representations. Medicinal Plants. Environmental Education.

1 Doutora em Educação. Grupo de Pesquisa Conscientização Ambiental. Professora do Programa de Pós Graduação em Saúde e Meio Ambiente e do Mestrado em Educação da Univille. Rua Paulo Malschitzk, 10 - Zona Industrial Norte, Joinville/SC. CEP: 89219-710. Tel: (47) 3461-9000. Email: $<$ nelmabaldin47@gmail.com>.

2 Mestre em Saúde e Meio Ambiente da Univille. Farmacêutica e Bioquimica. Rua Paulo Malschitzk, 10 - Zona Industrial Norte, Joinville/SC. CEP: 89219-710. Tel: (47) 3461-9000. Email: <acosta. patricia1975@gmail.com>.

R. Educ. Públ.

Cuiabá

v. 27

n. 64

p. $159-178$

jan./abr. 2018 


\section{Introdução}

Ao longo da história o homem sempre esteve em contato com a natureza e dela tirou o alimento, o habitat e também as substâncias com fins curativos para tratar as doenças de seus povos. Esse conhecimento, milenar, foi sendo repassado para as geraçóes que se seguiram, constituindo assim o que denominamos patrimônio histórico cultural imaterial, que, nos dias atuais, cada vez mais se confronta com o acelerado desenvolvimento das cidades. Desenvolvimento que leva à industrializaçáo, à urbanização e a mudanças nos estilos de vida das pessoas, ocasionando com isso um distanciamento das tradiçóes e hábitos preservados pelos antigos familiares.

Mas, apesar dessas questóes advindas da modernidade, o uso de plantas medicinais ainda é encontrado, e isso a par do avanço tecnológico e científico da medicina convencional e do desenvolvimento de novos tratamentos e descobertas de novos medicamentos. Isso ocorre principalmente nas comunidades ruralizadas e afastadas dos grandes centros, nas mais diversas populaçóes do mundo. Muito provavelmente isto ocorre devido à procura por tratamentos que sejam alternativos e naturais e que não provoquem tantos efeitos colaterais ou tóxicos, como os da medicina tradicional, ou, então, pelo valor econômico muito inferior que o tratamento com as plantas medicinais proporciona (CEOLIN et al., 2011).

Nesse contexto, o objetivo do artigo é analisar quais as representaçóes sociais, culturais e econômicas do patrimônio cultural imaterial uso popular de plantas medicinais em uma pequena comunidade rural - Comunidade Estrada Mildau, localizada nos arredores da cidade de Joinville, em Santa Catarina. Em específico, trabalhou-se com crianças dessa comunidade que frequentavam regularmente o $5^{\circ}$ ano do ensino fundamental da Escola Rural Municipal Eugênio Klug e suas respectivas mães e avós. Objetivos decorrentes e específicos foram também estudados, tais como: reconhecer nas falas das crianças e de suas mães e avós a representação social, cultural e econômica do uso popular de plantas medicinais; avaliar se o conhecimento popular está sendo transmitido das avós para as mães e delas para seus descendentes diretos (crianças); e listar, para revisóes posteriores, as plantas medicinais mais utilizadas pelos moradores da comunidade onde foi aplicada a pesquisa. Para tanto, o estudo fundamentou-se na teoria das representaçóes sociais e no método fenomenológico (HUSSERL, 2006; MOSCOVICI, 2009).

A pesquisa foi respaldada em trabalhos já realizados com o mesmo objeto de estudo, como a análise de Veiga Junior (2008), que destaca como são raros os estudos que avaliam o grau de utilização das plantas medicinais e a sua inserção na 
cultura popular. Já em Levantamento Etnobotânico de Plantas Medicinais nos quintais do bairro Novo Horizonte, Ituiutaba, MG, Liporacci e Simão (2013) enfatizam outra questão: tratam da relevância do conhecimento das plantas medicinais pela população rural e da importância da divulgação desse conhecimento. Outros estudos também se destacam nesse mesmo sentido, como os de Badke et al. (2012) e Heisler et al. (2012), que revelam como o conhecimento cultural é transmitido entre os familiares de grupos sociais distintos e, dessa maneira, perpetuado.

No entanto, a par dos estudos já realizados, durante a fase da revisão bibliográfica para a pesquisa, observou-se a falta de investigaçóes no campo das representaçóes sociais, questão específica na tradição do uso de plantas medicinais. Por esse motivo entende-se a relevância da pesquisa realizada.

Denotou-se a importância da contribuição dos participantes da pesquisa para o entendimento da representação do uso popular das plantas medicinais em relação às três gerações que contribuíram com o estudo. Com essas participações, obteve-se um panorama geral do conhecimento sobre o uso dessa alternativa de tratamento das doenças para as famílias, bem como percebeu-se o significado e a importância desses saberes para a comunidade estudada.

Importante considerar, nesse sentido, que em nenhum momento o estudo teve como objetivo realizar uma identificação etnobotânica das plantas medicinais encontradas na comunidade estudada. Portanto, durante toda a pesquisa a nomenclatura utilizada pelas pesquisadoras, quando se referem às plantas medicinais, baseia-se conforme a denominação popular, aquela utilizada na própria comunidade.

\section{As representações sociais e a Fenomenologia}

A teoria das representações foi proposta pelo sociólogo Émile Durkheim (1858-1917), que buscou evidenciar a força da expressão do pensamento social - do coletivo - em relação ao pensamento individual. Para Durkheim, as representaçóes são um conceito que mantém as sociedades coesas e unidas e, em sua visão, as sociedades são centradas na coesão sobre os indivíduos. Ou seja, Durkheim partiu do coletivo para o individual, por isso chamou sua teoria de Representaçóes Coletivas (FAGUNDES, 2009).

$\mathrm{Na}$ década de 1960, o psicólogo romeno naturalizado francês, Moscovici (1929-2014), reintroduziu nos meios acadêmicos o termo representaçóes, porém, atribuiu-lhe outro significado. Moscovici deixou de lado o conceito que as representaçóes tinham em Durkheim, no sentido do coletivo, e incorporou uma representação de cunho social e fenomenológico ao conceito, ou seja, conduziu o 
estudo das representaçóes para o cotidiano dos atores sociais. Moscovici, portanto, conferiu, à teoria, o caráter social (REIS; BELLINI, 2011).

Nesse encaminhamento, para Moscovici, as representações não são um conceito estático de uma comunidade, mas um fenômeno em constante transformação, dependendo das ideias, crenças e habitus dos atores sociais (MOSCOVICI, 2009). E essa mobilidade das representaçóes atribuída por Moscovici é garantida pela comunicação e pela troca de ideias, valores, diversidades culturais, saberes e histórias de vida entre os sujeitos sociais. Quando interagem entre si, as representaçóes vão tomando forma, pois cada ator social contribui com seus saberes anteriores, que vão se agrupando e convergindo e podem levar a um consenso.

Logo, as representaçôes são situações processuais que vão sendo construídas e tomam conta da realidade social, que vai se tornando comum a todos os sujeitos de uma comunidade. Assim, as representaçóes sociais são formadas ao longo do tempo mediante a comunicação entre os atores sociais com o intuito de identificar, nomear e tornar o objeto algo que tenha um sentido comum a todos (JODELET, 1989; MOSCOVICI, 2009).

É importante destacar, portanto, que a teoria das representaçóes sociais foi um amplo projeto de Moscovici para buscar o entendimento da influência do conhecimento científico na cultura e no pensamento comum das pessoas e onde essas pessoas se encaixam no mundo em que vivem para, então, terem condiçóes de compreendê-lo.

Um melhor entendimento do fundamento das representaçóes sociais alicerçase na fenomenologia ou no estudo dos fenômenos, uma vez que as representaçóes sociais são fenômenos que envolvem os atores sociais. Entre os mais diversos estudiosos da fenomenologia, grande destaque até os dias de hoje se dá ao filósofo alemão Husserl (1859-1938). Para Husserl, a fenomenologia deve ser entendida como a ciência que estuda a realidade, os eventos reais que possuem uma existência efetiva e fazem parte da vida dos sujeitos sociais que pertencem ao "[...] mundo espaço-temporal [...]" (HUSSERL, 2006, p. 23).

Husserl ainda salienta que a fenomenologia náo deve ser compreendida como apenas a ciência dos fatos, mas como a ciência das essências (ciência eidética), dos fenômenos. Fenômenos esses que nas sociedades são transcendentalmente reduzidos. Para alcançar o fenômeno na sua essência Husserl criou o método da redução fenomenológica ou, como descreve Zilles (2007, p. 18), Husserl criou o "[...] efeito epoqué ou redução à esfera transcendental, onde surgem as vivências puras, a consciência pura." Para chegar à redução fenomenológica Husserl considerou que a existência do mundo exterior ou dos preconceitos e pressupostos devem ser suspensos, para, assim, alcançar a essência do fenômeno a partir de sucessivas reduçóes fenomenológicas (ZILLES, 2007). 
Ao conceituar o método da redução fenomenológica Husserl (2006, p. 27, grifo do autor) esclarece:

O método de redução fenomenológica está em conformidade e com o qual poderemos remover as barreiras cognitivas inerentes à essência de todo modo natural de investigar, diversificando a direção unilateral própria ao olhar até obtermos o livre horizonte dos fenômenos 'transcendentalmente' purificados e, com ele, o campo da fenomenologia em nosso sentido próprio.

Para Silva et al. (2008) é por meio da redução fenomenológica que se alcançam as estruturas intencionais. Esse processo possibilita o entendimento de que, à medida que os autores colocam entre parênteses ou em suspensão o fato e deixam aflorar as ideias e os sentidos desse fato por meio da consciência, estão se permitindo acolher o mundo e os sujeitos (atores sociais) como fenômenos representados. Daí, as representaçóes sociais.

\section{Uso popular de plantas medicinais: patrimônio cultural imaterial}

Segundo a Agência Nacional de Vigilância Sanitária (ANVISA), as plantas medicinais são aquelas que têm a função de aliviar as doenças comuns e são extensamente usadas pelas comunidades em geral na forma in natura, sem sofrer nenhum processo de industrialização (ANVISA, 2010). Ao receber um processo de industrialização, a planta medicinal passa a ser conhecida como medicamento e a ser chamada de fitoterápico. Nesse campo, deve obedecer a regras de fabricação bem como de fiscalização por órgãos competentes, como a própria ANVISA, os quais determinam o processo e a qualidade do produto.

Sabe-se da relevância das plantas medicinais na vida das pessoas desde tempos muito remotos, quando o homem tinha apenas como fonte de recurso de cura a natureza, que lhe provia com os elementos necessários para restaurar suas condiçóes físicas, mentais e espirituais. O conhecimento sobre o uso terapêutico das plantas medicinais foi sendo adquirido pelo homem a partir do uso cotidiano e da experimentação nas pessoas adoentadas, e também nas saudáveis. Assim, foi se aprendendo e formando-se toda uma gama de saberes sobre as plantas medicinais e que vem transpassando incontáveis geraçóes (TESKE; TRENTINI, 2001). 
Muito se perdeu desse conhecimento no passar dos séculos, mas também saberes novos foram sendo agregados aos velhos conhecidos e, dessa forma, os saberes foram sendo renovados. Nesse caminho percorrido pela humanidade, o uso das plantas medicinais tornou-se popular e entendido como um patrimônio cultural imaterial.

Patrimônio cultural imaterial são todas as manifestaçóes populares que decorrem das tradiçóes e costumes que acontecem desde muito tempo em determinadas regióes ou comunidades, e por serem imateriais ou intangíveis, distinguem-se dos monumentos históricos que são bens materiais. Podem ser religiôes, danças, festas, culinárias, habitus, representações, conhecimentos, saberes, músicas... São todos patrimônios culturais imateriais valorados pelas pessoas, transmitidos aos seus descendentes e que fazem parte da cultura de um povo (GONÇALVES, 2002).

Entre essas crenças, pode-se destacar o uso popular que fazem as pessoas das plantas medicinais praticamente desde o início da história do Homem, e com a finalidade de tratar e aliviar as enfermidades. Embora, ainda, esse saber, esse bem imaterial, não conste oficialmente nos registros como um patrimônio cultural imaterial, ele assim é considerado, tendo em vista a característica de intangibilidade e do benefício concedido a todas as pessoas que se abastecem de seus efeitos terapêuticos (GONÇALVES, 2002).

A manutenção, a preservação e a herança de um patrimônio cultural imaterial dependem particularmente do conhecimento e da transmissáo do seu valor às geraçóes que se seguem.

\section{Metodologia}

A pesquisa foi aplicada numa abordagem qualitativa, do tipo descritivo e participativo e também foi referendada pela abordagem quantitativa mediante a aplicação de questionário com perguntas abertas e fechadas com vistas à coleta dos dados.

Gonçalves et al. (2014) expressam que a pesquisa qualitativa é a modalidade em que o pesquisador se utiliza da possibilidade de analisar o contexto socioeconômico e cultural de forma que melhor relate a expressão social. Desse modo, há uma maior interaçáo e envolvimento entre o pesquisador e os participantes, o que facilita a busca dos significados que representam a realidade para os sujeitos, e essa realidade é obtida mediante a comunicação recíproca.

Esse entendimento é também reforçado por Ludke e André (2013), que consideram a aproximação pesquisador-pesquisados uma ação permitida pela 
pesquisa qualitativa e a veem como uma possibilidade de uma análise detalhada e descritiva de situaçóes subjetivas a partir das falas dos sujeitos pesquisados. Essa aproximação, esclarecem as autoras, compóe uma abordagem do objeto de estudo muito mais direta e estreita e, por isso, a pesquisa do tipo qualitativo tem um caráter de descrição (LUDKE; ANDRÉ, 2013).

A característica ampla e flexível da pesquisa qualitativa tem como ênfase a compreensão do viver situações e não apenas as suas definições ou conceitos. É uma compreensão voltada para os significados do perceber, ou seja, refere-se às manifestaçóes sobre as percepçóes que o sujeito tem do objeto de pesquisa, as quais se expressam pelo próprio sujeito que as percebe (MINAYO et al., 2007). Esse caráter da pesquisa qualitativa está em contraposição à metodologia quantitativa, que busca controlar a subjetividade, a emoção e a interatividade com os sujeitos. Em outras palavras, a pesquisa quantitativa requer objetividade e controle do pesquisador em todas as etapas do estudo (GONÇALVES et al., 2014).

Nesse embate teórico entre as duas abordagens metodológicas, percebeu-se a ausência de pesquisas no campo das representaçóes sociais específicas para a questão da tradição do uso das plantas medicinais como forma alternativa de tratamento à saúde. Nessa direção, entende-se a relevância da pesquisa realizada ao buscar as representaçóes nos aspectos social, econômico e cultural do uso popular das plantas medicinais em uma comunidade rural. Entende-se ainda que a maior ênfase dessa pesquisa tenha sido manifestada na metodologia qualitativa. No entanto, embora o lastro teórico tenha sido embasado na fenomenologia e nas orientaçôes da pesquisa qualitativa, na aplicação do estudo utilizaram-se as duas abordagens metodológicas. Minayo e Sanches (1993) enfatizam que, embora a pesquisa qualitativa tenha diferenças em relação à pesquisa quantitativa no método e nos instrumentos de trabalho, ambas não se excluem, mas se complementam.

\section{Coleta dos dados - caracterizando o locus da pesquisa e os participantes}

A pesquisa foi aplicada na localidade conhecida como Comunidade Estrada Mildau, pertencente à zona rural do Distrito de Pirabeiraba, na cidade de Joinville, Santa Catarina. Como se lê em Branderburg (2009), a Estrada Mildau é a comunidade mais estruturada da zona rural do Distrito de Pirabeiraba. Tem aproximadamente 3 km de extensão, com início na Rodovia SC-301 e término no Morro da Tromba, sendo que sua via principal é asfaltada, e abriga a maioria dos moradores que possui melhores condiçóes socioeconômicas. A comunidade também dispóe de vias transversais, onde residem os moradores em condiçóes menos favoráveis. 
A instalação da Comunidade Estrada Mildau aconteceu no ano de 1870 com a chegada de imigrantes alemáes, que arrendaram as terras daquela área e passaram a colonizá-las por meio da agricultura e da exploração da madeira (BRANDERBURG, 2009). Hoje a comunidade mantém-se fiel às tradições de origem, sendo constituída por descendentes dos primeiros colonizadores e formada por 150 famílias de pequenos agricultores, donas de casa e trabalhadores da zona industrial de Pirabeiraba. A comunidade conta com a Escola Rural Municipal Eugênio Klug, que abriga as crianças da localidade do $1^{\circ}$ ao $5^{\circ}$ ano do ensino fundamental. Para a comunidade, essa escola é um ponto de referência importante uma vez que é a única na regiáo. Esse é o motivo da escolha dessa localidade e sua escola como locus para a realizaçáo do estudo.

Objetivando identificar a relação que a Comunidade Estrada Mildau tem com o uso caseiro de plantas medicinais no tratamento de suas doenças, e assim buscar o entendimento de quais as representaçóes sociais, culturais e econômicas as pessoas que ali vivem e fazem uso dessa medicina alternativa têm desse bem imaterial, bem como observar o como está acontecendo a transmissão do conhecimento sobre o uso das plantas medicinais nessa comunidade, elaboraram-se determinadas questóes que foram aplicadas na forma de questionário: A família cultiva plantas medicinais em casa? Quais as plantas medicinais cultivadas? Quais as plantas medicinais mais utilizadas? Qual o modo de preparo mais comum de usar a planta medicinal? Para quais doenças as plantas medicinais são comumente utilizadas?

A coleta dos dados ocorreu em duas fases distintas: a primeira, acontecida nas residências das famílias, com o grupo das mães e avós, quando foi aplicado o questionário semiestruturado e, após finalizada essa etapa, ocorreram conversas informais com essas senhoras que possibilitaram um contato mais estreito entre as pesquisadoras e as famílias, seguindo-se às orientaçóes expressas em Thiollent (2011). As respostas do questionário e as conversas informais foram todas registradas no caderno de campo das pesquisadoras. Esse é um recurso importante da pesquisa qualitativa, que faculta a possibilidade de haver uma maior compreensão a partir das falas dos sujeitos, o que facilita o entendimento de suas crenças, seus sentimentos, e de captar as lembranças relacionadas à temática em discussão (MINAYO, 2013; THIOLLENT, 2011). A segunda fase da pesquisa ocorreu na escola, e somente com as crianças. Essa etapa foi dividida em três atividades sequenciais: aplicação do questionário (as crianças registraram as suas respostas no próprio formulário), apresentação de uma palestra sobre o uso tradicional de plantas medicinais e aplicação de um jogo educativo (caça-palavras), com o objetivo de observar as reaçôes e percepções das crianças quanto ao tema em estudo. 
Os dois grupos que compuseram a pesquisa, um deles formado somente por alunos do $5^{\circ}$ ano do ensino fundamental da já referida escola (18 crianças), e o segundo grupo composto por 17 mães e três avós das respectivas crianças, totalizaram 38 sujeitos participantes. Todos são moradores da área rural na Estrada Mildau e aceitaram espontaneamente participar da pesquisa. Para tanto, assinaram o Termo de Consentimento Livre e Esclarecido, respeitando, assim, os critérios estabelecidos pelo Comitê de Ética da Universidade da Região de Joinville (Univille), que avaliou o projeto, e também visando atender às determinaçóes previstas na Resolução CNS 466/2012.

Das crianças que participaram desse estudo dez são meninos e oito são meninas com idades entre nove a 11 anos. As mães compreendem a faixa etária de 29 a 35 anos e as avós de 55 a 68 anos de idade. Quanto à profissão que exercem, das 17 máes, oito delas responderam ser do lar, as demais trabalham no comércio local e duas são aposentadas.

A participação das crianças e suas respectivas mães e avós possibilitou verificar a importância que representa, para essa comunidade, o uso caseiro das plantas medicinais como forma de tratamento alternativo, e também para o entendimento de como se dá o processo de transmissão do conhecimento desse saber entre as três geraçóes.

No caso da transmissão do conhecimento sobre o uso das plantas medicinais, diversos estudos, como a pesquisa levada a efeito por Ceolin et al. (2011), por exemplo, dão a compreensão de que ocorre mais comumente entre as mulheres da família. Essa, portanto, é a justificativa para a inclusão das mulheres (mães e avós) no estudo, haja vista que a transmissibilidade do conhecimento é considerada de extrema importância para a perpetuação do patrimônio cultural imaterial de um povo.

Para uma melhor compreensão do formato que se deu para a análise dos dados coletados, bem como para a ênfase nas respostas dos participantes da pesquisa, neste artigo demonstram-se as avós com a letra $V$, seguida do número de ordem de aplicação do questionário, por exemplo $V 1$, e assim por diante. Utilizaram-se o mesmo procedimento para as mães, com a letra $M$; para as crianças com a letra $A$ e, por último, a letra $F$ para as Famílias.

\section{Os resultados}

No contexto da pesquisa, $80 \%$ das mães e avós participantes responderam que cultivam algum tipo de planta medicinal em casa e $20 \%$ (especialmente as mães) responderam que não têm o hábito de cultivarem sistematicamente essas plantas. Quanto às crianças, 66,7\% relataram que as famílias cultivam sim 
plantas medicinais em casa e 33,3\% que não as cultivam. Logo, entende-se que essa prática caseira pode facilitar o uso das plantas medicinais para o tratamento de enfermidades uma vez que as famílias, ao cultivá-las, têm um livre acesso a essas plantas.

As mães e avós afirmaram que cultivam em casa as seguintes plantas medicinais: Alecrim, Alface, Alfavaca, Arnica, Arruda, Babosa, Boldo, Camomila, Capim-limão, Carqueja, Erva cidreira, Gengibre, Goiabeira, Guaco, Hortelã, Limão, Louro, Losna, Manjerona Mamoeiro e Maracujá. Dentre todas as plantas que foram citadas ao longo da aplicação da pesquisa, algumas espécies foram consideradas as mais citadas pela comunidade: Hortelā, Goiabeira, Limão, Camomila, Boldo, Erva cidreira e o Guaco. Ao analisar essa relação das plantas mais citadas pelos participantes da pesquisa compreende-se que a comunidade faz uso das plantas medicinais para tratar enfermidades comuns, como, por exemplo, doenças dos sistemas digestivo, nervoso, respiratório e urinário. Resultados esses que encontram respaldo em outros estudos executados na mesma linha de pesquisa, como os de Rezende e Cocco (2002), Vendruscolo e Mentz (2006) e Brasileiro et al. (2008).

Considerando-se que a grande maioria da população adulta da comunidade, representada na pesquisa pelas mães e avós das crianças participantes, tem alguma espécie de planta com fins medicinais cultivada em suas moradias, procurou-se entender qual a forma mais comum do uso dessas plantas no tratamento caseiro de enfermidades. Denotou-se que $91,4 \%$ dos respondentes consideraram como a mais importante forma de preparo medicinal a popularmente conhecida como chá, ou infusão, seguida de emplastro. A forma de preparo das plantas medicinais como chás é também referenciada em diversos estudos na mesma linha da pesquisa aplicada, como se lê em Rezende e Cocco (2002), Vendruscolo e Mentz (2006) e Santos et al. (2008).

Durante a realizaçáo do estudo houve a possibilidade de elaborar uma listagem das plantas medicinais citadas pelos participantes e relacioná-las com as doenças para as quais são utilizadas na comunidade. Como o demonstrado no Quadro 1, as mães, as avós e as crianças relataram 18 enfermidades que são tratadas com as plantas medicinais caseiras e com fins preventivos ou curativos: verminoses (6), cólicas intestinais (4), diarreias (3), cólicas estomacais (3), fígado/hepatite (9), inflamação (5), tosse (3), calmante (8), insônia (2), infecção (1), emagrecimento (1), afta (1), dor de cabeça (1), cicatrização (2), dor na bexiga (1), bronquite (1), dor de garganta (2) e gripe (2). 


\section{Quadro 1 - Relação Enfermidades citadas com uso caseiro de plantas medicinais indicadas para a cura}

\begin{tabular}{|c|c|c|}
\hline Enfermidades & $\begin{array}{l}\mathrm{N}^{\circ} \text { de } \\
\text { citações }\end{array}$ & $\begin{array}{l}\text { Planta Medicinal mais usada (na } \\
\text { forma de "chás") }\end{array}$ \\
\hline Verminoses & 6 & Camomila, hortelã e mamoeiro \\
\hline Cólicas intestinais & 4 & Erva cidreira e camomila e manjerona \\
\hline Diarreia & 3 & Folha de goiabeira \\
\hline Cólicas estomacais & 3 & Arruda, boldo e losna \\
\hline Fígado/hepatite & 9 & Boldo, losna e arruda \\
\hline Inflamação & 5 & Erva cidreira e arnica \\
\hline Tosse & 3 & Guaco, hortelã, gengibre e limão \\
\hline Calmante & 8 & Erva cidreira, camomila e maracujá \\
\hline Insônia & 2 & Erva cidreira, camomila, maracujá e alface \\
\hline Infecção & 1 & Erva cidreira e gengibre \\
\hline Emagrecimento & 1 & Guaco, carqueja \\
\hline Afta & 1 & Folha de goiabeira e carqueja \\
\hline Dor de cabeça & 1 & Erva cidreira, camomila \\
\hline Cicatrização & 2 & $\begin{array}{c}\text { Folha de goiabeira e } \\
\text { Arnica (na forma de emplastro) }\end{array}$ \\
\hline Dores na bexiga & 1 & Camomila \\
\hline Bronquite & 1 & Guaco, hortelã, gengibre e limão \\
\hline Dor de garganta & 2 & Guaco, hortelã, gengibre e limão \\
\hline Gripe & 2 & Guaco, hortelã, gengibre e limão \\
\hline
\end{tabular}

Fonte: As autoras, 2016

Com esses resultados, e utilizando-se dos recursos da metodologia quantitativa, houve a possibilidade de agrupar essas enfermidades conforme o sistema corporal a que se referiam com a finalidade de se obter um melhor entendimento sobre para quais grupos de doenças a comunidade faz uso das plantas medicinais. Foram encontradas 25 citaçóes referentes ao sistema digestivo, dez citaçóes para sistema nervoso, oito citaçôes para sistema respiratório, uma citação para o sistema urinário e nove citaçóes foram consideradas como outros (Figura 1).

Percebeu-se, então, que a Comunidade Estrada Mildau faz maior uso das plantas medicinais para tratar ou aliviar as doenças do sistema digestivo, com $47 \%$ das respostas; que 19\% utilizam plantas medicinais para o sistema nervoso; 
15\% utilizam para o sistema respiratório; e 2\% utilizam para o sistema urinário dados, corroborados com outros estudos já realizados, como os de Vendruscolo e Mentz (2006), Brasileiro et al. (2008) e Liporacci e Simão (2013).

Figura 1 - Representação das doenças tratadas pela comunidade com plantas medicinais

$\begin{array}{ll}\square \text { SIST. DIGESTIVO } & \text { SIST. NERVOSO } \\ \square \text { SIST. URINÁRIO } & \text { OUTROS }\end{array}$

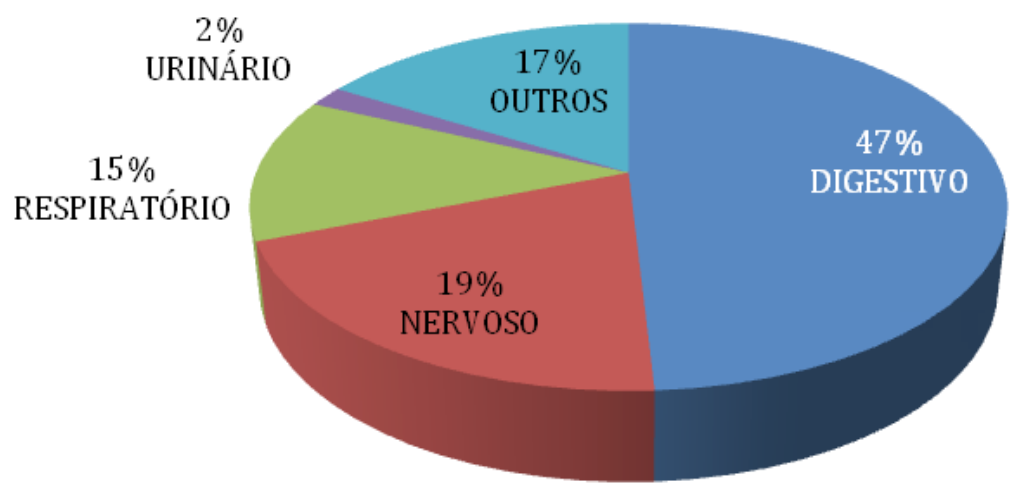

Fonte: As autoras, 2016

Relacionando-se o uso das plantas medicinais pelas mães e avós com as manifestaçôes das crianças, percebeu-se como se processa a transmissão do conhecimento sobre esse uso na comunidade estudada.

A transmissão de um conhecimento para as próximas geraçôes é de fundamental importância para que esse conhecimento, no caso de um patrimônio cultural imaterial, por exemplo, mantenha-se vivo e preservado. Gonçalves (2002) expressa que a conservação da herança cultural depende de dois fatores extremamente relevantes: o conhecimento e a transmissão do seu valor para as geraçóes que se seguem.

Como pode ser observado na pesquisa, $87,0 \%$ de citações referentes às avós e às mães demonstram que elas são as detentoras e transmissoras desse conhecimento para seus descendentes. Esse resultado é condizente com os demais estudos científicos realizados na mesma linha de estudo, como descrito nos trabalhos de Santos et al. (2008), Ceolin et al. (2011) e Badke et al. (2012). Os dados, portanto, revelam e confirmam o que já foi apontado pela literatura revista para essa pesquisa: a base do conhecimento e da transmissão do saber do uso das 
plantas medicinais realmente é de responsabilidade das mulheres, principalmente as mulheres da família.

Foi possível também realizar uma análise de como ocorre essa transmissão do conhecimento entre as três geraçóes participantes da pesquisa, como o demonstrado na Figura 2.

Figura 2 - Representação da transmissão do conhecimento sobre as plantas medicinais nas respostas dos participantes

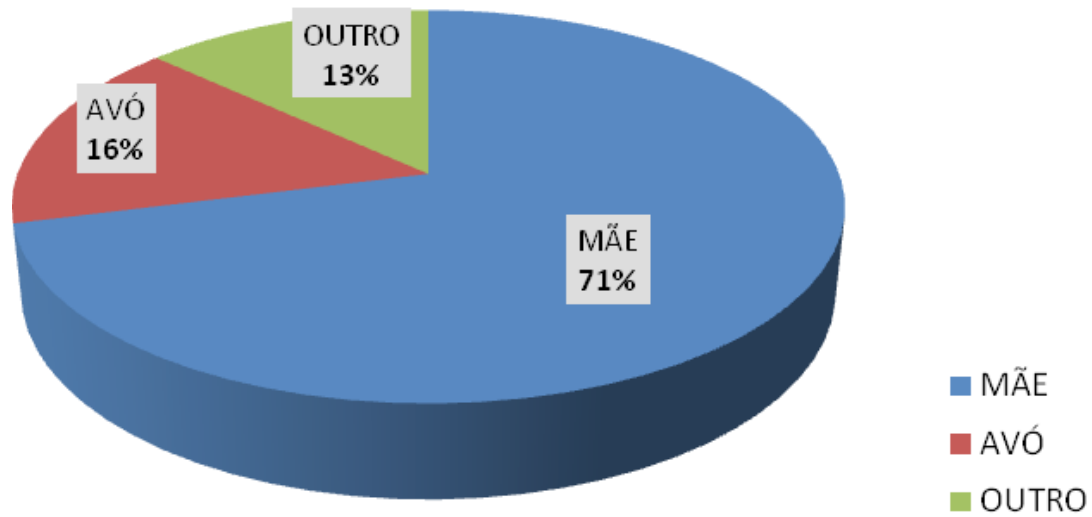

Fonte: As autoras, 2016

Analisando-se a Figura 2 percebe-se que a transmissão do conhecimento sobre o uso das plantas medicinais está ocorrendo de maneira verticalizada na comunidade estudada, considerando-se que $87 \%$ dos participantes confirmaram tê-la recebido de suas máes ou de suas avós. Importante considerar que nas três famílias que têm as avós convivendo presentemente no seio familiar, a transmissão do conhecimento se deu de maneira ainda mais acentuada, haja vista a presença da avó, que reforça a passagem do legado, principalmente para as crianças.

Nesse sentido, entende-se que está ocorrendo a transmissão do conhecimento entre as três geraçóes dos habitantes da Estrada Mildau, e que esse conhecimento está sendo repassado verbalmente entre os membros das famílias. 


\section{Representação social do uso das plantas medicinais}

Para melhor compreender a amplitude fenomenológica da representação social do uso caseiro das plantas medicinais para as pessoas que vivem na Comunidade Estrada Mildau, buscou-se avaliar a importância cultural desse patrimônio imaterial para essa população. O uso de plantas medicinais em nosso país remonta ao período ainda anterior à época da colonização, tendo em vista que os povos indígenas já faziam uso e respeitavam os poderes curativos da natureza. A análise dos dados da pesquisa levou em consideração essa base histórica e três aspectos quanto às representaçóes: social, cultural e econômico.

Para a totalidade das avós participantes do estudo a representação do uso popular das plantas medicinais tem um significado tradicional, ou seja, as avós consideram que esse é um legado que lhes foi transmitido por suas mães e suas avós e que deve ser mantido para as futuras geraçóes, como citam as participantes V1: Acho que a vida da gente sem as plantas é como se faltasse um pedaço da gente [sic]; e V2: Desde criança eu sempre tomei os chás feitos com as plantas da horta da casa dos meus pais.

Essa é uma situação também encontrada em outros estudos, como o de Badke et al. (2012), que referem à relação de afeto que as avós sentem ao lembrarem-se do tempo em que eram crianças e suas próprias mães cuidavam da saúde da família com as plantas. Brasileiro et al. (2008) também se referem acerca da detenção do conhecimento sobre as plantas medicinais estar intimamente ligada às emoçóes das avós.

Dentre as mães, $53 \%$ delas consideram que o uso popular das plantas medicinais tem uma importância social, ou seja, relacionam a preferência pelo uso dessa terapia na comunidade por ser mais natural e provocar menos efeitos colaterais que a medicina convencional. A resposta de $M 16$ é um exemplo: É o meio mais natural de cuidar da familia, é muito importante essa pesquisa para as crianças aprenderem mais sobre as plantas. Ainda, $41 \%$ das mães consideram relevante a tradição como representação para o uso popular das plantas medicinais e 5,9\% delas consideram que é importante usar as plantas medicinais em vista do aspecto econômico, como relata M8: Tem de usar as plantas da horta como remédio, porque na farmácia os remédios são muito caros.

Esses resultados demonstram uma diferença no juízo de valor do bem cultural - uso popular das plantas medicinais como forma de tratamento alternativo - entre as avós e as mães. Amorozo (1995) esclarece que a transmissão de uma tradição requer um contato íntimo e contínuo entre as geraçóes para que se fixe e faça parte da cultura de uma comunidade. Como observado nos resultados da pesquisa, a grande maioria das mães participantes apenas recebeu o conhecimento de suas mães, mas não mantém um contato contínuo e prolongado com elas para maiores 
informaçóes acerca desse saber. Esse detalhe da falta de maiores informaçóes sobre os poderes curativos das plantas medicinais foi possível de ser percebido durante as visitas domiciliares para a aplicação do questionário, considerando que apenas três avós moram na comunidade, e as demais residem em outras localidades, por vezes bastante distantes, de modo que os encontros familiares não são frequentes. Esse fenômeno do pouco contato entre mães e avós levou à percepção de que o fato de náo ter ocorrido essa influência materna de forma mais incisiva propiciou a uma certa relativizaçáo quanto à valoração da tradição do uso caseiro das plantas medicinais, particularmente em relação às mulheres da Estrada Mildau.

A baixa média de idade das mães também pode ter sido um fator de influência nas representaçóes que elas têm do bem cultural, levando-as a conceder uma maior importância social e cultural sobre outra temática qualquer, quando questionadas, que não sejam os valores tradicionais recebidos de suas mães, como o uso caseiro de plantas medicinais.

Em relaçáo às crianças, $56 \%$ delas entendem que a transmissão do bem cultural tem valor social, $39 \%$ acreditam no valor cultural e 5\% apontam o valor econômico. Percebeu-se que os resultados encontrados com as crianças praticamente igualaramse aos resultados encontrados com suas mães, demonstrando, assim, um certo equilíbrio nessa relação mãe e filhos. No entanto, deve-se analisar, nesse caso, duas questóes: a primeira, quanto ao valor que as crianças deram ao social. Pela análise das respostas do questionário e da reflexão sobre as percepçóes das pesquisadoras quanto às reaçóes das crianças sobre a temática em estudo, constatou-se que elas pensam no social no sentido pragmático, pois, do ponto de vista desses participantes, se há planta medicinal em casa, então a mãe deve usá-la quando se faz necessário, como citou A9: Temos plantado em casa, então é mais fácil usar. Por sua vez, $A 4$ expressou: Se é bom para a saúde e tem na horta de casa, a gente usa [sic], ao que $A 13$ contestou: As plantas não são só para a nossa casa, nós também distribuimos para os vizinhos quando eles precisam.

$\mathrm{Na}$ mesma linha de pensamento, diversas outras crianças demonstraram esse raciocínio do uso social da planta medicinal. Mas também há aquelas que compreendem que o uso das plantas medicinais significa um tratamento mais natural do que tomar remédios, como manifestou $A 2$.

Apenas uma criança respondeu que a representação do uso das plantas medicinais tem expressão econômica, o que condiz com o relato da sua mãe $(M 8)$. Nas palavras dessa criança, tomar o chá das plantas é melhor porque a gente não gasta com remédios. $(A 8)$. Entende-se que para essa família a possibilidade de fazer uso de um tratamento natural, que utiliza um recurso oriundo de sua própria localidade e é cultivado por eles mesmos, pode ter uma representação que vai além de ato de economizar com medicamentos para tratar as doenças da família. Essa é uma 
questão que envolve uma rede de outras questóes, tais como evitar afastar-se do trabalho para levar o familiar ao médico e, ainda, náo raro, pode ocorrer de o profissional médico prescrever medicamentos que não constam na rede pública de saúde e a família necessitar custear o tratamento recorrendo à farmácia tradicional.

Essa análise referente à família de $M 8$ e $A 8$ de certa forma pode ser estendida para as demais famílias da Estrada Mildau, pois, mesmo sem perceberem, essas famílias estáo economizando no orçamento doméstico ao cultivarem e usarem as plantas medicinais para o tratamento de suas enfermidades, apesar de o resultado estatístico desse dado não ter sido significativo em percentuais para a pesquisa.

Importante analisar as considerações obtidas nas três residências que têm a avó, mãe e criança no mesmo seio familiar ( $F 1, F 6$ e $F 11)$, no sentido de se observar a representação social que têm essas famílias quanto às plantas medicinais quando essas três geraçôes convivem juntas. $\mathrm{Na} F 11$ a representação social do uso caseiro das plantas medicinais é cultural, ou seja, consideram uma tradição. Já na $F \sigma$ a mãe e a avó acham que a representação das plantas medicinais também é um hábito, uma cultura, no entanto, quando a criança foi interpelada sobre essa questão, respondeu que para si as plantas medicinais são importantes e têm um significado social e prático, ou seja, como temos a planta em casa é mais cômodo usá-la. (AG).

Nesse caso, embora ocorra o convívio entre as três geraçóes, observa-se que para a criança o significado do uso caseiro das plantas medicinais é pragmático, pois não tem o mesmo valor que representa para sua mãe e avó. Mas essa e é uma situação possível, e como apontou Moscovici (2009), as representaçóes são constantemente modificadas e acolhem as alteraçóes conforme o tempo e o local onde se manifestam. Pelegrini e Funari (2009) relatam que os valores patrimoniais e os juízos de preservação desses valores tendem a mudar com o passar do tempo, uma vez que essas são situaçóes construídas social e historicamente. A referência justificou as diferenças nos resultados obtidos com as análises comparativas entre as manifestaçóes das três geraçóes.

\section{Considerações Finais}

A descoberta das virtudes terapêuticas das plantas pelas civilizaçóes foi acontecendo empiricamente, baseando-se nas experimentações que os sábios das comunidades faziam nas pessoas com enfermidades, uma vez que praticamente era esse o único recurso que dispunham para tratar suas moléstias.

Esse saber empírico, ao ser praticado cotidianamente na vida das pessoas, foi sendo então transmitido ao longo das gerações, e assim permanece vivo até os dias de hoje como forma de patrimônio cultural imaterial, pertencente à categoria dos saberes e crenças que fazem parte da vida de um povo. 
No entanto, percebe-se que com o progresso, o desenvolvimento das cidades e as mudanças nos estilos de vida das pessoas essa tradição cultural do uso caseiro de plantas medicinais está cada vez mais perdendo espaço para a medicina tradicional. Dessa forma, recua dos grandes centros para as localidades rurais, mais afastadas, que tendem a manter ainda vivas as crenças e tradiçóes de sua população, como é o caso da Comunidade da Estrada Mildau.

A intervenção da pesquisa na Comunidade Estrada Mildau proporcionou uma sensibilização nas crianças participantes do estudo e em suas famílias, em especial para o ato da reflexão sobre o uso caseiro das plantas medicinais e o que esse hábito representa para a comunidade. Por isso, entende-se que os objetivos traçados para a pesquisa foram alcançados, pois a comunidade despertou seu olhar para a questâo do entendimento do que são plantas medicinais, a sua real importância para as famílias na prevenção e tratamento de doenças e no valor de manter a tradição desse uso. Mas, principalmente, o maior destaque se deu no entendimento e na compreensão de que as plantas medicinais fazem parte do patrimônio cultural imaterial daquela população e localidade.

Com a pesquisa, houve a possibilidade de se construir um panorama de como se apresenta nesse momento histórico a representaçáo social do uso popular das plantas medicinais na comunidade estudada, e isso se deu a partir dos questionamentos com as três geraçóes participantes, todas moradoras da zona rural da localidade.

Nesse contexto, percebeu-se que está ocorrendo uma alteração no juízo de valor entre as primeira e segunda geraçóes dessa comunidade. Essa mudança de valores da geração das avós para a geração das mães fica explícita quando se analisam os dados encontrados para as representaçóes sociais, culturais e econômicas do uso das plantas medicinais. Para as avós, o maior significado está ligado às suas raízes, às memórias da infância, aos velhos tempos, pois são crenças transmitidas por suas mães e avós como uma herança cultural. Por isso, as avós entendem que esse saber faz parte de suas vidas e, consequentemente, transmitiram tal saber aos seus filhos, filhas e também netos.

Para as mães e as crianças, as representações sociais, culturais e econômicas resultaram em valores aproximados, sendo que o mais significativo, tanto para as mães quanto para as crianças, centrou-se no social. Pode-se compreender que na segunda e na terceira geraçóes está ocorrendo a influência do momento histórico e cultural que essas duas geraçóes estão construindo, muito diferente do tempo em que suas mães e avós foram criadas e das influências recebidas de seus familiares. Ou seja, atualmente os tempos são outros e, por isso, os valores e as representaçóes também vão acompanhando as mudanças da sociedade e assim se alterando. 
Como enfatizado por Moscovici (2009), as representaçóes sociais não são estáticas, e justamente por isso, elas estáo em constante transformação, dependendo dos fenômenos e do momento que os atores sociais estão vivendo. Mesmo estando a Comunidade Estrada Mildau localizada em uma área rural ela recebe as influências do avanço da modernidade. A tecnologia chega, por exemplo, por meio da televisão e da escola. É notável a representação que essa nova geração tem desse bem cultural imaterial que é utilizado na sua comunidade e cuja interpretação que fizeram é diferente de como interpretaram suas máes e especialmente suas avós, que viveram grande parte de suas vidas em outra época cultural e social.

Entende-se a importância dessa pesquisa uma vez que busca compreender a representação social do uso popular das plantas medicinais em uma comunidade rural. E percebe-se também a importância da pesquisa para a própria comunidade, que, ao envolver-se no estudo, resultou sensibilizada e estimulada a pensar no bem cultural que utiliza cotidianamente, mas que não tinha conhecimento da importância cultural da sua conservação como tradição.

Nesse sentido, a partir dos dados e do panorama geral da representaçáo social do uso caseiro das plantas medicinais encontradas na Estrada Mildau, recomendase uma futura intervenção na área e que seja amparada, essa intervenção, na Educação Ambiental e na Educação Patrimonial.

Espera-se que esse estudo seja focado nas famílias, e principalmente nas crianças, para que, bem embasados, esses atores sociais possam, via um conhecimento mais aprofundado, proteger essa tradição, que transpassou geraçóes para chegar até o momento presente. E que essa tradição tenha prosseguimento em seu caminho de valoração desse bem cultural tâo significativo para a humanidade como são as plantas medicinais.

\section{Referências}

AMOROZO, M. C. M. A abordagem etnobotânica na pesquisa de plantas medicinais. In: DI STASI. L. C. (Org.). Plantas medicinais: arte e ciência. Um guia de estudo interdisciplinar. São Paulo: UNESP, 1995. p. 47-59.

AGÊNCIA NACIONAL DE VIGILÂNCIA SANITÁRIA - ANVISA. Uso de plantas medicinais da tradiçáo popular, 2010. Disponível em: <http://www. anvisa.gov.br>. Acesso em: 21 jan. 2015.

BADKE, M. R; et al. Saberes e práticas populares de cuidado em saúde com o uso de plantas medicinais. Texto Contexto Enfermagem, Florianópolis, v. 21, n. 2, p. 363-70, abr./jun. 2012. 
BRANDENBURG, B. Estradas e famílias - colonização de Pirabeiraba. Revista Pirabeiraba 150 anos, Joinville, p 15-20, abr, 2009.

BRASILEIRO, B. G. et al. Plantas medicinais utilizadas pela população atendida no "Programa de Saúde da Família". Revista Brasileira de Ciências Farmacêuticas Brazilian Journal of Pharmaceutical Sciences, Governador Valadares, MG, Brasil, v. 44, n. 4, out. /dez. 2008.

CEOLIN, T. et al. Plantas medicinais: transmissão do conhecimento nas famílias de agricultores de base ecológica no Sul do RS. Revista Escola de Enfermagem - USP, São Paulo, v. 45, n. 1, p. 47-54, 2011.

ESCOLA MUNICIPAL EUGÊNIO KLUG (EMEK). Disponível em: <http:// www.emeugenioklug.blogspot.com.br, 2015>. Acesso em: 20 ago. 2015.

FAGUNDES, B. A teoria das representaçóes sociais nos estudos ambientais. Revista RA'E GA, Curitiba, n. 17, p. 129-137, ago. 2009.

GONÇALVES, J. R. S. Memórias e patrimônio: ensaios contemporâneos. In: REUNIÃOANUALDAASSOCIAÇÃONACIONALDEPÓS-GRADUAÇÃO EM CIÊNCIAS SOCIAIS, 26., 2002, Caxambu. Mesa Redonda... Caxambu: Editora DP \& A, 2002. p. 21-24.

GONÇALVES, M. L. Fazendo Pesquisa: do Projeto à Comunicação Científica. 4. ed. Ver. e ampl. Joinville: Univille, 2014.

HEISLER, E. V. et al. Saber popular sobre a utilização da planta anredera cordifolia (folha gorda). Texto Contexto Enfermagem, Florianópolis, v. 21, n. 4, p. $937-$ 44. out./dez., 2012.

HUSSERL, E. Ideias para uma fenomenologia pura e para uma filosofia fenomenológica. Tradução Márcio Suzuki. 3. ed. São Paulo: Ideias \& Letras. 2006.

JODELET, D. Représentations Sociales: um domaineem expansion. In: D. Jodelet (Ed). Les représentations sociales. Paris: PUF, 1989. p 31-61. Tradução de Tarso Bonilha Mazzotti. Revisão técnica de Alda Judith Alves Mazzotti. Rio de Janeiro: UFRJ. Faculdade de Educação, 1993.

LIPORACCI, H. S. N; SIMÃO, D.G. Levantamento etnobotânico de plantas medicinais nos quintais do bairro Novo Horizonte. Revista Brasileira de Plantas Medicinais, Campinas, v. 15, n. 4, p. 529-540, 2013.

LUDKE, M.; ANDRÉ, M. E. D. A. Pesquisa em Educaçáo. 2. ed. Rio de Janeiro: EPU. 2013.

MINAYO, M. C. S. O desafio do conhecimento: pesquisa qualitativa em saúde. 13. ed. São Paulo: Hucitec, 2013. 
MINAYO, M. C. S. et al. Pesquisa social: teoria, método e criatividade. 25. ed. Petrópolis: Vozes, 2007.

MINAYO, M. C. S.; SANCHES, O. Quantitativo-Qualitativo: Oposição ou Complementaridade? Cadernos de Saúde Pública, Rio de Janeiro, v. 9, n. 3, p. 239-262, jul/set. 1993.

MOSCOVICI, S. Representaçóes Sociais. Investigaçóes em Psicologia Social. 3.ed. Petrópolis: Vozes, 2009.

PELEGRINI, S. C. A; FUNARI, P. P. A. O que é patrimônio cultural imaterial. 3. Reimpressão. São Paulo: Editora Brasiliense, 2009.

REIS, S. L. A; BELLINI, M. Representaçóes sociais: teoria, procedimentos metodológicos e educação ambiental. Revista Acta Scientiarum Humanand Social Sciences, Maringá, v. 33, n. 2, p. 149-159. 2011.

REZENDE, H. A.; COCCO, M. I.M. A utilização de fitoterapia no cotidiano de uma população rural. Revista Escola de Enfermagem, São Paulo, v. 36, n. 3, p. 282-8, 2002.

SANTOS, J. F. L; AMOROZO, M. C. M; MING, L. C. Uso popular de plantas medicinais na comunidade rural da Vargem Grande, Município de Natividade da Serra, SP. Revista Brasileira Plantas Medicinais, Botucatu, v. 10, n. 3, p. 67-81, 2008.

SILVA, J. M. O.; LOPES, R. L. M; DINIZ, N. M. F. Fenomenologia. Revista Brasileira de Enfermagem, Brasília, DF, v. 61, n. 2, p. 254-257, mar./abri. 2008.

TESKE, M.; TRENTINI, A. M. M. Compêndio de Fitoterapia. 4. ed. Curitiba: Herbarium Laboratório Botânico Ltda, 2001. 317p.

THIOLLENT, M. Metodologia da pesquisa-açáo. 18. ed. São Paulo: Cortez, 2011.

VEIGA JUNIOR, V.F. Estudo do consumo de plantas medicinais na região centro-norte do estado do Rio de Janeiro: aceitação pelos profissionais de saúde e modo de uso pela população. Revista Brasileira de Farmacognosia. v. 18, n. 2, p. 308-313, abr./jun. 2008.

VENDRUSCOLO, G. S; MENTZ, L. A. Levantamento etnobotânico das plantas utilizadas como medicinais por moradores do Bairro Ponta Grossa. Porto Alegre, Rio Grande do Sul, Brasil. Iheringia, sér. botânica, Porto Alegre, v. 61, n. 1-2, p. 83-103, jan./dez. 2006.

ZILLES, Urbano. Fenomenologia e teoria do conhecimento em Husserl. Revista da Abordagem Gestáltica. Goiânia, v. 13, n. 2, p. 216-221, 2007.

Recebimento em: 11/01/2016.

Aceite em: 18/10/2016. 